\title{
JPN Guidelines for the management of acute pancreatitis: treatment of gallstone-induced acute pancreatitis
}

\author{
Yasutoshi Kimura ${ }^{1}$, Tadahiro Takada ${ }^{2, *}$, Yoshifumi Kawarada ${ }^{3}$, Koichi Hirata ${ }^{1}$, Toshihiko Mayumi ${ }^{4}$, \\ Masahiro Yoshida ${ }^{2}$, Miho Sekimoto ${ }^{5}$, Masahiko Hirota ${ }^{6}$, Kazunori Takeda ${ }^{7}$, Shuji IsajI ${ }^{8}$, Masaru Koizumi ${ }^{9}$, \\ Katsusuke Satake ${ }^{10}$, Makoto Otsuki ${ }^{11, * *}$, and Seiki Matsuno ${ }^{12, * * *}$ \\ ${ }^{1}$ First Department of Surgery, Sapporo Medical University School of Medicine, S-1, W-16, Chuo-ku, Sapporo, Hokkaido 060-8543, Japan \\ ${ }^{2}$ Department of Surgery, Teikyo University School of Medicine, Tokyo, Japan \\ ${ }^{3}$ Ueno Municipal Hospital, Mie, Japan \\ ${ }^{4}$ Department of Emergency and Critical Care Medicine, Nagoya University Graduate School of Medicine, Nagoya, Japan \\ ${ }^{5}$ Department of Healthcare Economics and Quality Management, Kyoto University Graduate School of Medicine, Kyoto, Japan \\ ${ }^{6}$ Department of Gastroenterological Surgery, Kumamoto University Graduate School of Medical Science, Kumamoto, Japan \\ ${ }^{7}$ Department of Surgery, National Hospital Organization Sendai Medical Center, Sendai, Japan \\ ${ }^{8}$ Department of Hepatobiliary Pancreatic Surgery and Breast Surgery, Mie University Graduate School of Medicine, Mie, Japan \\ ${ }^{9}$ Ohara Medical Center Hospital, Fukushima, Japan \\ ${ }^{10}$ Department of Surgery, Kinki University School of Medicine, Osaka, Japan \\ ${ }^{11}$ Department of Gastroenterology and Metabolism, University of Occupational and Environmental Health, Japan, School of Medicine, \\ Kitakyushu, Japan \\ ${ }^{12}$ Division of Gastroenterological Surgery, Tohoku University Graduate School of Medicine, Sendai, Japan
}

\begin{abstract}
Gallstones, along with alcohol, are one of the primary etiological factors of acute pancreatitis, and knowledge of the etiology as well as the diagnosis and management of gallstones, is crucial for managing acute pancreatitis. Because of this, evidence regarding the management of gallstone-induced pancreatitis in Japan was collected, and recommendation levels were established by comparing current clinical practices with optimal clinical practices. The JPN Guidelines for managing gallstone-induced acute pancreatitis recommend two procedures: (1) an urgent endoscopic procedure should be performed in patients in whom biliary duct obstruction is suspected and in patients complicated by cholangitis (Recommendation A); and (2) after the attack of gallstone pancreatitis has subsided, a laparoscopic cholecystectomy should be performed during the same hospital stay (Recommendation B).
\end{abstract}

Key words Gallstone pancreatitis - Emergency endoscopy · Laparoscopic cholecystectomy

Offprint requests to: $\mathrm{Y}$. Kimura

* President, Japanese Society of Emergency Abdominal Medicine; President, Japanese Society of HepatoBiliary-Pancreatic Surgery; President, Asian-Pacific Hepato-Pancreato-Biliary Association

** Chairman, Intractable Pancreatic Disease Investigation and Research Group of the Japanese Ministry of Health, Labour, and Welfare

*** President, Japan Pancreas Society

\section{Clinical questions}

CQ1. Is an emergency endoscopy approach beneficial in the treatment of gallstoneinduced acute pancreatitis?

CQ2. Is one-stage cholecystectomy followed by common bile duct (CBD) clearance safer and more effective than endoscopic procedures?

CQ3. When should laparoscopic cholecystectomy be undertaken in patients with gallstone pancreatitis?

\section{Introduction}

Research on the pathophysiology of acute pancreatitis has advanced dramatically during the past 20 years, and, as the number of randomized controlled studies (RCTs) of severe acute pancreatitis has steadily increased, mainly in the United States and Europe, evidencebased management has come to be demanded for acute pancreatitis. In Japan, three institutions - the Japanese Society for Abdominal Emergency Medicine, the Japan Pancreas Society, and the Research Group for Intractable Diseases and Refractory Pancreatic Diseases, which is sponsored by the Japanese Ministry of Health, Labour, and Welfare - collaborated to publish "Evidence-based clinical practice guidelines for acute pancreatitis: proposals." ${ }^{1}$ This article incorporates the latest evidence in relation to gallstone pancreatitis and 
presents these guidelines (the JPN Guidelines) for the treatment of gallstone-induced acute pancreatitis, citing the relevant Recommendations.

\section{Management of bile duct stones in gallstone- associated acute pancreatitis}

\section{Clinical questions (CQ) 1. Is an emergency endoscopy approach beneficial in the treatment of gallstone-induced acute pancreatitis?}

An emergency endoscopy approach is beneficial in patients with acute pancreatitis in whom bile duct obstruction is suspected or there are complications from cholangitis (Recommendation A)

Emergency endoscopic approaches to the management of bile duct stones in gallstone-associated acute pancreatitis include endoscopic sphincterotomy (ES), endoscopic papillary balloon dilation (EPBD), endoscopic nasobiliary drainage (ENBD), and stenting. Those procedures are performed to remove gallstones and to drain the bile duct, which mostly results in relieving the obstruction of the pancreatic duct. The endoscopic approach seems to be most beneficial in those patients with acute pancreatitis suspected of having concomitant gallstones complicated with the occurrence or exacerbation of jaundice, and in patients complicated by cholangitis. The decision whether or not to perform one-stage choledocholithotomy after ES or endoscopic biliary drainage must be based on the pathophysiological condition of the patient and the skill of the physician. It is important to refer any patient who requires an endoscopic approach to an advanced medical unit if the patient meets the criteria for transfer (see page $\mathbf{\square}$ ).

Emergency or early endoscopic procedures for acute pancreatitis have been assessed in four randomized controlled trials (RCTs; Level 1b),,$^{2-5}$ and a metaanalysis of these RCTs has been performed (Level 1a). ${ }^{6}$ The metaanalysis involved a total of 834 patients, comprising 460 patients treated by endoscopic retrograde cholangiopancreatography (ERCP) followed by ES (ERCP/ES group) and 374 patients treated conservatively (conservative treatment group). The analysis led to the conclusion that the ERCP/ES group had lower incidences of morbidity and mortality (Table 1), but because pancreatitis patients with treated by ERCP or ES alone have never been analyzed, it remains unclear whether ERCP or ES is more useful.

The results of two studies (Level 1b) ) $^{2,3}$ that published data stratified by severity indicate that ERCP/ES is not very useful in patients with mild pancreatitis (Table 2), and a report expressing a negative opinion in regard to early endoscopic treatment (Level 1b) ${ }^{5}$ excluded patients with jaundice from the analysis, and the percentage of subjects with gallstone pancreatitis was only $19 \%$. It is concluded from these reports that urgent $\mathrm{ERCP} / \mathrm{ES}$ is useful only in severe gallstone pancreatitis.

However, there are differences in severity assessment, particularly of severe cases, between Japan and Western countries, and no convincing evidence supporting the application of emergency ERCP/ES in patients with severe cases has been established in Japan. It is currently thought that the indications for emergency ERCP/ES should be restricted to patients suspected of having prolonged biliary duct obstruction, as manifested by the occurrence or exacerbation of jaundice, and to patients complicated by cholangitis. Various other techniques besides ERCP/ES are used for biliary drainage and are generally accepted in Japan. A report, entitled "Evaluation of urgent treatment for impacted bile duct stones" (published in 1992 in Japanese), claims that endoscopic nasobiliary drainage (ENBD) is a useful and safe urgent treatment method for impacted bile duct stones, although no high-quality evidence supported by RCTs or metaanalysis has yet emerged to support that report.

In terms of the safety of ERCP/ES in the acute stage of pancreatitis, no difference has been found between the incidence of complications after early intervention (within $48 \mathrm{~h}$ of onset) and the incidence after delayed intervention (Level 3b), ${ }^{7}$ and it has been reported that $\mathrm{ERCP} / \mathrm{ES}$ within 24 to $72 \mathrm{~h}$ after onset is safe (Level

Table 1. Reported morbidity and mortality rates in early ERCP/ES and conservative treatment groups

\begin{tabular}{|c|c|c|c|c|}
\hline \multirow[b]{2}{*}{ Author } & \multicolumn{2}{|c|}{ Morbidity (\%) } & \multicolumn{2}{|c|}{ Mortality (\%) } \\
\hline & ERCP/ES group & $\begin{array}{l}\text { Conservative } \\
\text { treatment group }\end{array}$ & ERCP/ES group & $\begin{array}{l}\text { Conservative } \\
\text { treatment group }\end{array}$ \\
\hline Neoptolemos ${ }^{2}$ & 16.9 & 33.9 & 1.7 & 8.1 \\
\hline $\operatorname{Fan}^{3}$ & 17.5 & 28.6 & 5.2 & 9.2 \\
\hline Nowak $^{4}$ & 16.9 & 36.3 & 2.3 & 12.8 \\
\hline Folsch $^{5}$ & 46.0 & 50.9 & 11.1 & 6.3 \\
\hline Pooled data & 25.0 & 38.2 & 5.2 & 9.1 \\
\hline
\end{tabular}

(cited from Sharma and Howden ${ }^{6}$, with some modifications) 
Table 2. Reported morbidity and mortality rates in early ERCP/ES and conservative treatment groups, stratified according to severity

\begin{tabular}{|c|c|c|c|c|c|c|}
\hline \multirow[b]{2}{*}{ Author } & \multicolumn{3}{|c|}{ ERCP/ES group } & \multicolumn{3}{|c|}{ Conservative treatment group } \\
\hline & $\begin{array}{c}\text { Number of } \\
\text { patients }\end{array}$ & $\begin{array}{c}\text { Morbidity } \\
\text { (\%) }\end{array}$ & $\begin{array}{l}\text { Mortality } \\
\text { (\%) }\end{array}$ & $\begin{array}{c}\text { Number of } \\
\text { patients }\end{array}$ & $\begin{array}{c}\text { Morbidity } \\
\text { (\%) }\end{array}$ & $\begin{array}{c}\text { Mortality } \\
(\%)\end{array}$ \\
\hline \multicolumn{7}{|c|}{ Mild pancreatitis group } \\
\hline Neoptolemos ${ }^{2}$ & 34 & 4 & 0 & 34 & 4 & 0 \\
\hline $\mathrm{Fan}^{3}$ & $56\left(34^{a}\right)$ & $8\left(6^{\mathrm{a}}\right)$ & 0 & $58\left(35^{\mathrm{a}}\right)$ & $6\left(6^{\mathrm{a}}\right)$ & 0 \\
\hline Pooled data & 90 & $12\left(13^{a}\right)$ & 0 & 92 & $10\left(11^{\mathrm{a}}\right)$ & 0 \\
\hline \multicolumn{7}{|c|}{ Severe pancreatitis group } \\
\hline Neoptolemos ${ }^{2}$ & 25 & 6 & 1 & 28 & 17 & 5 \\
\hline $\mathrm{Fan}^{3}$ & $41\left(30^{\mathrm{a}}\right)$ & $9\left(4^{a}\right)$ & $5\left(1^{a}\right)$ & $40\left(28^{\mathrm{a}}\right)$ & $23\left(15^{\mathrm{a}}\right)$ & $9(5)$ \\
\hline Pooled data & 66 & $15\left(23^{a}\right)$ & $6\left(9^{a}\right)$ & 68 & $40\left(59^{a}\right)$ & $14\left(21^{a}\right)$ \\
\hline
\end{tabular}

${ }^{a}$ Patients with CBD stones followed-up with ERCP

2b). ${ }^{8}$ Similar results were reported in a retrospective study of a large number of patients (Level 4). ${ }^{9}$ The four RCTs referred to above ${ }^{2-5}$ have suggested bleeding as a complication of ERCP/ES, but the bleeding occurred in only a few patients with mild pancreatitis and was never a direct cause of death. Based on the reports from overseas, we cannot conclude that ERCP/ES is highly risky in the acute stage of pancreatitis. According to the results of a third nationwide survey in Japan (in 2000) of accidental complications from gastrointestinal endoscopy (Level 4), the incidence of accidental complications of ERCP performed for examination purposes and of ES done to treat the papilla of Vater was $0.1 \%$ and $0.7 \%$, respectively, and the mortality rate was $0.006 \%$ and $0.048 \%$, respectively. The issue of whether or not ERCP/ES is indicated should be carefully evaluated and adequate care should be taken to prevent accidental complications. Effective performance obviously requires an advanced medical institution with experienced specialists and a special unit whose staff is capable of carrying out emergency ERCP/ES examinations and dealing with bleeding and other complications.

\section{Surgical approach}

CQ2. Is one-stage cholecystectomy followed by common bile duct (CBD) clearance safer and more effective than endoscopic procedures?

Open choledochotomy or sphincterotomy (operative removal of CBD stones is recommended) (Recommendation D)

In Japan, choledocholithotripsy with emergency endoscopic procedures (ES, EPBD) is performed by endoscopists, as well as by many surgeons, and it has become the treatment of first choice for CBD clearance. One-stage cholecystectomy and CBD clearance has not been demonstrated to be safer and more effective than endoscopic procedures, and it is not recommended in either the JPN Guidelines or the International Association of Pancreatology (IAP) guidelines. ${ }^{10}$

CQ3. When should laparoscopic cholecystectomy be undertaken in patients with gallstone pancreatitis?

Laparoscopic cholecystectomy should be considered after recovery from an attack of gallstone pancreatitis and should be performed during the same hospital stay (choledochotomy and CBD clearance are performed as required) (Recommendation $B$ )

Cholelithiasis is one of the major causes of acute pancreatitis, and gallstone-induced acute pancreatitis is an absolute indication for cholecystectomy (and choledochotomy, when necessary). However, there has been no consensus regarding the timing of this surgical intervention. One RCT claims that the earlier surgery is performed after onset, the more beneficial it is, while another RCT has proposed delayed surgery once the inflammatory process has subsided. The latter RCT (Level 1b) ${ }^{11}$ compared earlier surgery (within $72 \mathrm{~h}$ of hospital admission) and delayed surgery, and the results suggested that the earlier surgery was more beneficial. Because the results showed no significant difference in the incidence of complications $(8.3 \%$ vs $10.3 \%)$ or the mortality rate $(2.8 \%$ vs $6.9 \%)$, this RCT concluded that surgery on the bile duct system with the aim of removing the cause of the pancreatitis or preventing its progression could be performed safely even in the acute state. According to another RCT (Level 1b), ${ }^{12}$ which is often quoted as grounds to justify delayed surgery, patients subjected to early surgery (within $48 \mathrm{~h}$ of hospitalization) had a significantly higher complication rate (30.1\% vs $5.1 \%)$ and mortality rate $(15.1 \%$ vs $2.4 \%)$ than those subjected to delayed surgery. This conflicting evidence may be explained by potential differences in the severity of the disease in the patients included in the 
Table 3. Prospective cohort studies of laparoscopic cholecystectomy employed for gallstone-associated acute pancreatitis

\begin{tabular}{|c|c|c|c|c|c|c|c|c|}
\hline Author & $\begin{array}{c}\text { Number } \\
\text { of } \\
\text { patients }\end{array}$ & $\begin{array}{l}\text { Timing of } \\
\text { surgery } \\
\text { (days } \\
\text { after } \\
\text { onset) }\end{array}$ & $\begin{array}{c}\text { Completion } \\
\text { rate } \\
(\%)\end{array}$ & $\begin{array}{c}\text { Conversion } \\
\text { rate } \\
(\%)\end{array}$ & $\begin{array}{l}\text { Operation } \\
\text { time } \\
(\mathrm{min})\end{array}$ & $\begin{array}{c}\text { Morbidity } \\
(\%)\end{array}$ & $\begin{array}{l}\text { Mortality } \\
(\%)\end{array}$ & $\begin{array}{c}\text { CBD } \\
\text { exploration }^{\mathrm{d}}\end{array}$ \\
\hline Rhodes et al. ${ }^{16}$ & 16 & $10(4-34)^{\mathrm{a}}$ & 100 & 0 & $50(30-120)$ & 0 & 0 & $15 / 1$ \\
\hline Tate et al. ${ }^{17}$ & 24 & $7(3-24)^{a}$ & 87.5 & 12.5 & 76 (NA) & 8 & 0 & $23 / 0$ \\
\hline $\begin{array}{l}\text { Ballestra-Lopez } \\
\text { et al. }{ }^{18}\end{array}$ & 40 & $3.4 / 15^{\mathrm{b}, \mathrm{c}}$ & 100 & 0 & $86(45-210)^{\mathrm{a}}$ & 10 & 2.5 & $0 / 40$ \\
\hline Ricci et al. ${ }^{19}$ & 51 & NA & 100 & 0 & NA & 1.9 & 0 & $40 / 47$ \\
\hline Uhl et al. ${ }^{20}$ & 48 & $10(4-29)^{\mathrm{a}}$ & 79 & 21 & $80(30-225)^{\mathrm{a}}$ & 7.9 & 0 & $0 / 33$ \\
\hline Chang et al. ${ }^{21}$ & 59 & NA & 100 & 0 & NA & 3.4 & 0 & $0 / 58$ \\
\hline
\end{tabular}

clinical trials. Discussion of the timing of surgery alone, without adequate consideration of the impact of severity, has caused confusion in clinical settings. However, the introduction of emergency ERCP/ES ${ }^{2,3}$ has completely changed the options available for the management of gallstone pancreatitis and has dramatically reduced the need for performing surgery in the acute stage.

There are two options in regard to delayed surgery: (i) surgery during the same hospital stay as that for the initial treatment, and (ii) surgery during rehospitalization after a sufficient recovery period. Because the rate of recurrence of pancreatitis during the recovery period after discharge is $32 \%$ to $61 \%$ (Level $3 \mathrm{~b}){ }^{13-15}$ patients with mild uncomplicated gallstone pancreatitis should undergo biliary tract exploration and cholecystectomy after the symptoms have been alleviated. Whenever possible, even patients with severe disease should undergo surgery during the same hospital stay as that for the initial treatment.

Laparoscopic cholecystectomy (LC) has been increasingly used to treat gallstone pancreatitis over the past 10 years. According to prospective cohort studies reported to date (Levels 1b-2c), ${ }^{16-21} \mathrm{LC}$ was associated with a completion rate of $94.5 \%$ (range, $79 \%$ to $100 \%$ ), a complication (morbidity) rate of $5.5 \%$ (range, $0 \%$ to $10 \%$ ), and a mortality rate of $0.4 \%$ (range, $0 \%$ to $2.5 \%$; Table 3), implying that LC resulted in performance equal to or better than that of laparotomy. Based on these results, the use of LC in mild gallstone pancreatitis is feasible and its clinical usefulness has been demonstrated.

The conventional standard surgical intervention for gallstone pancreatitis used to be open cholecystectomy and operative cholangiography, followed by choledochotomy when choledocholithiasis was observed. The introduction of LC, however, has made several options available for biliary tract exploration and the management of choledocholithiasis. Four typical procedures are:

1. ERCP/ES prior to surgery, and LC after diagnosing and removing CBD stones. In some patients, removal of CBD stones by ERCP/ES after LC.

2. Intraoperative cholangiography (IOC) during LC, and conversion to the open method when CBD stones are present.

3. IOC during LC, and when CBD stones are present, the addition of ES during or followed by LC.

4. LC, and laparoscopic choledochotomy/lithotripsy when CBD stones are discovered by IOC.

Procedure (1) has become increasingly popular in Japan. However, opinions differ concerning the application of ERCP in all patients with gallstone-associated pancreatitis. Some surgeons argue that ERCP should be performed only when choledocholithiasis is suspected on the basis of blood studies and other diagnostic imaging, or when it is diagnosed during IOC (Level 1b2b). ${ }^{21,22}$ The risk inherent in ERCP should be noted, particularly in patients with acute pancreatitis (Level 2b). ${ }^{23}$ It may be possible to substitute IOC for preoperative ERCP as a standard method to confirm those patients who are less likely to have choledocholithiasis, if the surgeons in charge of this procedure have sufficient experience and technique to perform IOC successfully. The choice of which of the above four procedures to opt for when choledocholithiasis is discovered by IOC depends on the skill and technique of the specialist physicians currently at each institution. Collection of more data on the safety, invasiveness, and completion rates associated with each of these procedures is an important task for the future. 


\section{References}

1. Mayumi T, Ura H, Arata S, Kitamura N, Kiriyama I, Shibuya K, et al. Evidence-based clinical practice guidelines for acute pancreatitis: proposals. J Hepatobiliary Pancreat Surg 2002;9:413-22.

2. Neoptolemos JP, Carr-Locke DL, London NJ, Bailey IA, James D, Fossard DP. Controlled trial of urgent endoscopic retrograde cholangiopancreatography and endoscopic sphincterotomy versus conservative treatment for acute pancreatitis due to gallstones. Lancet 1988;2:979-83.

3. Fan ST, Lai EC, Mok FP, Lo CM, Zheng SS, Wong J. Early treatment of acute biliary pancreatitis by endoscopic papillotomy. N Engl J Med 1993;328:228-32.

4. Nowak A, Nowakowska-Dulawa E, Marek TA, Rybicka J. Final results of the prospective, randomized, controlled study on endoscopic sphincterotomy versus conventional management in acute biliary pancreatitis (abstract). Gastroenterology 1995;108:A380.

5. Folsch UR, Nitsche R, Ludtke R, Hilgers RA, Creutzfeldt W. Early ERCP and papillotomy compared with conservative treatment for acute biliary pancreatitis. The German Study Group on Acute Biliary Pancreatitis. N Engl J Med 1997;336:237-42.

6. Sharma VK, Howden CW. Meta-analysis of randomized controlled trials of endoscopic retrograde cholangiography and endoscopic sphincterotomy for the treatment of acute biliary pancreatitis. Am J Gastroenterol 1999;94:3211-4.

7. Rosseland AR, Solhaug JH. Early or delayed endoscopic papillotomy (EPT) in gallstone pancreatitis. Ann Surg 1984;199:165-7.

8. Uomo G, Galloro V, Rabitti PG, Marcopido B, Laccetti M, Visconti M. Early endoscopic cholangiopancreatography and sphincterotomy in acute biliary pancreatitis: report of 50 cases. Ital J Gastroenterol 1991;23:564-6.

9. Aiyer MK, Burdick JS, Sonnenberg A. Outcome of surgical and endoscopic management of biliary pancreatitis. Dig Dis Sci 1999;44:1684-90.

10. Uhl W, Warshaw A, Imrie C, Bassi C, McKay CJ, Lankisch PG, et al. IAP guidelines for the surgical management of acute pancreatitis. Pancreatology 2002;2:565-73.

11. Stone HH, Fabian TC, Dunlop WE. Gallstone pancreatitis: biliary tract pathology in relation to time of operation. Ann Surg 1981;194:305-12.
12. Kelly TR, Wagner DS. Gallstone pancreatitis: a prospective randomized trial of the timing of surgery. Surgery 1988;104:600-5.

13. Ranson JH. The timing of biliary surgery in acute pancreatitis. Ann Surg 1979;189:654-63.

14. Frei GJ, Frei VT, Thirlby RC, McClelland RN. Biliary pancreatitis: clinical presentation and surgical management. Am J Surg 1986;151:170-5.

15. DeIorio AV Jr, Vitale GC, Reynolds M, Larson GM. Acute biliary pancreatitis. The roles of laparoscopic cholecystectomy and endoscopic retrograde cholangio-pancreatography. Surg Endosc 1995;9:392-6.

16. Rhodes M, Armstrong CP, Longstaff A, Cawthorn S. Laparoscopic cholecystectomy with endoscopic retrograde cholangiopancreatography for acute gallstone pancreatitis. Br J Surg 1993;80:247.

17. Tate JJ, Lau WY, Li AK. Laparoscopic cholecystectomy for biliary pancreatitis. Br J Surg 1994;81:720-2.

18. Ballestra-Lopez C, Bastida-Vila X, Bettonica-Larranaga C, Zaraca F, Catarci M. Laparoscopic management of acute biliary pancreatitis. Surg Endosc 1997;11:718-21.

19. Ricci F, Castaldini G, de Manzoni G, Borzellino G, Rodella L, Kind R. Minimally invasive treatment of acute biliary pancreatitis. Surg Endosc 1997;11:1179-82.

20. Uhl W, Muller CA, Krahenbuhl L, Schmid SW, Scholzel S, Buchler MW. Acute gallstone pancreatitis: timing of laparoscopic cholecystectomy in mild and severe disease. Surg Endosc 1999;13:1070-6.

21. Chang L, Lo S, Stabile BE, Lewis RJ, Toosie K, de Virgilio C. Preoperative versus postoperative endoscopic retrograde cholangiopancreatography in mild to moderate gallstone pancreatitis: a prospective randomized trial. Ann Surg 2000;231:82-7.

22. Rijna H, Borgstein PJ, Meuwissen SG, de Brauw LM, Wildenborg NP, Cuesta MA. Selective preoperative endoscopic retrograde cholangiopancreatography in laparoscopic biliary surgery. Br J Surg 1995;82:1130-3.

23. Loperfido S, Angelini G, Benedetti G, Chilovi F, Costan F, De Berardinis F, et al. Major early complications from diagnostic and therapeutic ERCP: a prospective multicenter study. Gastrointest Endosc 1998;48:1-10. 